\title{
The Influence of Basil Seed Hydroethanolic Extract on the Skin Wound Healing in Diabetic Male Rats
}

\author{
Mehran Hadi $^{1}$, Elham Moghtadaei-Khorasgani ${ }^{2}$, and Mohammad Hossein Etesamnia ${ }^{1}$ \\ ${ }^{I}$ Graduate in Veterinary Medicine, Shahrekord Branch, Islamic Azad University, Shahrekord, Iran \\ ${ }^{2}$ Department of Pathobiology, Shahrekord Branch, Islamic Azad University, Shahrekord, Iran \\ *Corresponding author's Email: moghtadaiee@gmail.com; (DORCiD: 0000-0002-8666-5104
}

\begin{abstract}
Diabetic wounds and cutaneous wounds are important issues in medical science. Basil is an herbaceous plant and has compounds such as terpenes, flavonoids, and antioxidant properties. A total of 50 male Wistar rats were allocated into 10 groups including the healthy group without treatment, the healthy group treated with $1 \%$ phenytoin, eucerin, 5\% basil seed extract, $10 \%$ basil seed, diabetic group without treatment, $1 \%$ phenytoin, eucerin. After anesthesia of rats, we made a $4 \mathrm{~cm}^{2}$ wound on the back of the animal, and different histopathological characteristics were examined, and also on days 3, 7, and 21 , the area of wounds was analyzed. In the healthy group treated with $10 \%$ basil seed extract, it was revealed that the wound size was significantly healed in the research days. In the diabetic rat groups, the decrease in the wound area was not significant and there was no significant difference between groups. Histopathological findings on day 21 in the healthy group treated with $10 \%$ basil seed extract revealed proper epidermis formation and relatively dense dermis containing collagen filaments. While in the diabetic groups, healing was slower. The results indicated that basil extract with anti-inflammatory and antioxidant characteristics can quicken the repair of cutaneous wounds.
\end{abstract}

Keywords: Basil, Diabetes, Histopathology, Wound

\section{INTRODUCTION}

Diabetes mellitus is the most prevalent endocrine disease that is related to carbohydrate, fat, and protein metabolism disorders. The disease results from the lack of cellular absorption of blood sugar because of diminished insulin or resistance of body cells to insulin (Siljander et al., 2019). Diabetes is a common reason for delayed or compromised wound healing. 15\% of individuals with diabetes mellitus develop lower-extremity ulcers (Walko et al., 2015). Cutaneous wounds and a decrease in their healing time are considered important concerns in medical and surgical sciences. Wound healing is an active process in which a series of associations take place between diverse cells, cytokine mediators, and extracellular matrix (Foo et al., 2017). which this process includes several stages. However, in general, it is a constant process, so that each stage overlaps with the next stage. These stages include coagulation, inflammation, proliferation, and resuscitation (Reinke and Sorg, 2012). Diabetes is a metabolic illness and leads to complications, such as neurological (neuropathy), ocular (retinopathy), and renal problems (nephropathy, Shahrokh et al., 2021). One of the most significant chronic complications of diabetes is diabetic foot ulcers, which can finally cause amputation. It is now well-known that diabetes leads to a rise in free radicals at the cell cytoplasm (Khaksar et al., 2011). Free radicals are very reactive because of their single electrons, and their excessive production causes damage in macromolecules such as DNA and proteins (Ibrahim et al., 2018). Research has revealed that antioxidants lessen DNA fragmentation caused by oxidative stress due to diabetes (Guo et al., 2020). It has been revealed that oral administration of vitamins E, C, and A improves plasma levels of antioxidant enzymes in diabetic patients. Various reports indicate that plants have many antioxidant compounds, such as different types of vitamins, carotenoids, and phenols (phenolic acids, flavonoids, and tannins) (Miri et al., 2020). Although diverse approaches are applied today to treat diabetic wounds, so far no efficient and without side effect treatment has been provided (Everett and Mathioudakis, 2018; Pourmahdi and Faedmaleki, 2021). In this regard, medicinal plants are of superior significance, because medicinal plants have rich sources of natural antioxidants that are utilized in traditional medicine to control and treat many skin diseases (Aziz et al., 2017). Currently, there is a serious trend to use medicinal plants because of the lack of side effects and the effective compounds in plants (Amalraj and Gopi, 2017).

Basil is a herbaceous, annual, fragrant plant from the family Lamiaceae, which is currently grown in most parts of Iran. Basil leaves can be utilized in many cases such as treating insomnia, healing of scratches, and as a painkiller (Veith et al., 2019). Basil contains numerous compounds such as terpenes, sesquiterpenoids, and flavonoids. Flavonoids have strong antioxidant characteristics (Denaro et al., 2020). The significance of basil is that besides flavor in food, its main active ingredient has antimicrobial effects and is efficient against different types of Gram-positive, Gram-negative 
pathogenic bacteria, molds, and yeasts. The antimicrobial impacts of basil extract are associated with its phenolic compounds. The most key phenolic compounds in basil are linalool and methyl chavicol (Adeli-Sardou et al., 2019). Consequently, basil extract because of its plentiful antioxidants and anti-inflammatory agents can be efficient in the healing process by stimulating angiogenesis (Gutiérrez-Grijalva et al., 2018). Therefore, this research aimed to examine the repairing effects of basil seed extract concerning its advantageous effects (anti-inflammatory, anti-apoptotic, and anti-free radical) on cutaneous wound healing in diabetic rats.

\section{MATERIALS AND METHODS}

\section{Ethical approval}

This is experimental laboratory research that was conducted in the Animal Research Laboratory of Shahrekord Azad University in 2019.

\section{Preparing extract}

If the substances in plant cells are extracted from plants with solvents such as water or organic solvents, this product is called an extract. If the extract is extracted with water or ethanol, it can be applied in medicines without eliminating the solvent. To prepare the extract, $500 \mathrm{~g}$ of plant seeds were added to $1000 \mathrm{ml}$ of $70 \%$ ethanol alcohol and incubated in a water bath at $45^{\circ} \mathrm{C}$ for 3 days in a container covered with aluminum foil. The extract was then separated by filter paper and a funnel and concentrated by vacuum distillation at $70{ }^{\circ} \mathrm{C}$ as much as possible (Mirjalili et al., 2017).

\section{Laboratory Animals}

For this research, 50 male rats with a specific weight range (200-250g) were obtained from the Laboratory Animal Breeding Center of Islamic Azad University, Shahrekord Branch, Iran. The rats were randomly allocated into ten groups of five rats. The rats were maintained in standard temperature conditions at $25-30^{\circ} \mathrm{C}$ and light conditions of 12 hours of light and 12 hours of darkness. Likewise, in terms of access to water and food and space away from pollution, the animals were in good condition, and to a high degree, all the principles in "Ethical Guide to Animal Research" were applied.

\section{Experimental design and grouping}

In this study, 50 male Wistar rats were allocated into 10 groups (healthy group without treatment, healthy group treated with $1 \%$ phenytoin, healthy group treated with eucerin, healthy group treated with 5\% basil seed extract, healthy group treated with $10 \%$ basil seed extract, diabetic group without treatment, diabetic group treated with $1 \%$ phenytoin, diabetic group treated with eucerin). To induce type 1diabetes in 5 groups of mice, intraperitoneal injection of streptozotocin made by Sigma Company of Germany was used at a dose of $50 \mathrm{mg} / \mathrm{kg}$ (Sadoughi, 2013). After anesthetizing the mice with an intraperitoneal injection of ketamine $(50 \mathrm{mg} / \mathrm{kg})$ and xylazine $(10 \mathrm{mg} / \mathrm{kg})$ (Pourmahdi and Faedmaleki, 2021), a wound of $4 \mathrm{~cm}^{2}$-width was created on the back of all animals in the experimental groups. Different histopathological characteristics were surveyed on days 3, 7, and 21, moreover, wound area was statistically analyzed on the same days according to Firoozeh et al. (2019).

\section{Data analysis method}

All values are reported as mean \pm S.E.M. and the statistical significance of differences among groups was assessed using one-way ANOVA. Tukey test was used to measure specific differences between pairs of means. A value of $p<$ 0.05 was considered significant.

\section{Ethical consideration}

Ethics committee approval was received for this study from the ethics committee of Shahrekord University, Iran, is IR.IAU.SHK.REC.10501972024).

\section{RESULTS AND DISCUSSION}

Morphological findings in the healthy group treated with $10 \%$ basil seed extract indicated a significant tendency to wound healing in the research days. This healing trend was followed in the phenytoin group with almost a similar rate. This wound healing in the $10 \%$ extract group on days 7 and 21 was significant ( $<0.05$ ), and in the phenytoin-treated 
group indicated a significant reduction on day $21(\mathrm{p}<0.05)$. Then, in the group treated with $5 \%$ extract and eucerin, the wound area was decreased at a slower rate and did not display a significant decrease $(\mathrm{p}>0.05)$. In the diabetic rat groups, the decrease in wound area was small and there was no significant difference between the groups. But in terms of a decrease in the wound area, the $10 \%$ basil extract and phenytoin groups had a better improvement (Graphs 1, 2, 3). Histopathological findings in this research indicated that on the third day, almost all groups had significant inflammation, edema, and bleeding. Tissue examination on day seven also revealed that in the healthy group treated with basil, the amount of inflammation was very small, little new blood vessels were formed, and collagen filaments have good density. While in the diabetic group, the number of collagen filaments was low and tissue had edema. On the 21 , in the healthy group treated with $10 \%$ basil extract, epithelium formation was proper and all-around, and relatively dense collagen filaments were visible in the tissue. While in the diabetic rat group treated with $10 \%$ basil extract, the epithelium was not formed properly and the collagen filaments were not in the required order and edema was considerable in the tissue. In general, based on the obtained results, particularly histopathologically, an excellent tendency to collagen formation and the lack of secondary infection in the site was witnessed, which is perhaps because of antimicrobial and anti-inflammatory characteristics and strong phenolic antioxidants in basil (Figure 1, Table 1). Wounds are clefts and modifications in the anatomical structure and activity of the skin. cutaneous wounds are caused by different reasons such as burns, mechanical injuries, etc. When a wound forms on the skin, a cellular reaction arises instantly. After a cutaneous wound, leukocytes are the first cells to appear at the wound site. After some hours, granulocytes and macrophages accumulate at the margin of the wound, and after a few days, the proliferation of derm begins and fibroblasts enter the area. Macrophages release compounds that lead to the attraction and proliferation of fibroblasts. Fibroblasts steadily replace most of the leukocytes, and collagen proliferation also enhances. The production of new vessels in wound tissue is essential for wound healing, and this process is affected by the mediators released by macrophages. The contractile phenomenon happens when fibronectin provides an appropriate substrate for cell migration and growth during granulated tissue development and attaches to myofibroblasts. Connects. After healing with collagen filaments, the wound site looks like the skin tissue before the wound is produced, and the blood and oxygen flow in the vessels of the wound site is increased through dilation of the arteries. Many efforts have been made to heal diabetic wounds, including:

In 2017, studied the influence of aqueous extract of Morus nigra fruit on wound healing in type 1 diabetic mice and the findings revealed that its fruit extract can quicken wound healing in diabetic mice. It also increases tissue repair indicators such as epithelial layer development and collagen layer density (Mirjalili et al., 2017). Bagheri et al. (2016) studied the effect of sesame alcoholic extract on the healing of diabetic wounds in male Wistar rats, and the results revealed that sesame alcoholic extract quickens the healing of cutaneous wounds in healthy and diabetic individuals.

Although diverse approaches are applied today to treat diabetic wounds, so far no efficient and without side effect treatment has been provided. In this regard, medicinal plants are of superior significance, because medicinal plants have rich sources of natural antioxidants that are utilized in traditional medicine in order to control and treat many skin diseases (Shahrokh et al., 2021). Currently, there is a serious trend to use medicinal plants because of the lack of different side effects and the effective compounds in plants (Denaro et al., 2020). Basil is a herbaceous, annual, fragrant plant from the family Lamiaceae, which is currently grown in most parts of Iran. Basil leaves can be utilized in many cases such as treating insomnia, healing of scratches, and as a painkiller. Basil contains numerous compounds such as terpenes, sesquiterpenoids, and flavonoids. Flavonoids have strong antioxidant characteristics (Salem et al., 2019). The significance of basil is that besides flavor in food, its main active ingredient has antimicrobial effects and is efficient against different types of Gram-positive, Gram-negative pathogenic bacteria, molds, and yeasts (Mostafavi et al., 2019). The antimicrobial impacts of basil extract are associated with its phenolic compounds. The most key phenolic compounds in basil are linalool and methyl chavicol (Filip, 2017). Consequently, basil extract because of its plentiful antioxidants and anti-inflammatory agents can be efficient in the healing process by stimulating angiogenesis (Brereton et al., 2015). Therefore, in this research, the repairing effects of basil seed extract on cutaneous wound healing in diabetic and healthy rats were evaluated concerning its advantageous effects (anti-inflammatory, anti-apoptotic, and antifree radical).

Histopathological findings in this research indicated that on the 3rd day, almost all groups had significant inflammation, edema, and bleeding. Tissue examination on day seven also revealed that in the healthy group treated with basil, the amount of inflammation was very small, little new blood vessels were formed, and collagen filaments have good density whreas the number of collagen filaments was low and tissue had edema in the diabetic group. On day 21, epithelium formation was proper and all-around, and relatively dense collagen filaments were visible in the tissue in the healthy group treated with $10 \%$ basil extract. However, in the diabetic rat group treated with $10 \%$ basil extract, the 
epithelium was not formed properly and the collagen filaments were not in the required order and edema was considerable in the tissue.

Morphological findings in the healthy group treated with $10 \%$ basil seed extract indicated a significant tendency to wound healing in the research days. This healing trend was followed in the phenytoin group with almost a similar rate. This wound healing in the $10 \%$ extract group on days 7 and 21 was significant $(\mathrm{p}<0.05)$, and in the phenytoin-treated group indicated a significant reduction on day $21(\mathrm{p}<0.05)$. Then, in the group treated with $5 \%$ extract and eucerin, the wound area was decreased at a slower rate and did not display a significant decrease $(\mathrm{p}>0.05)$.

In the diabetic rat groups, the decrease in wound area was small and there was no significant difference between the groups. But in terms of a decrease in the wound area, the $10 \%$ basil extract and phenytoin groups had a better improvement.

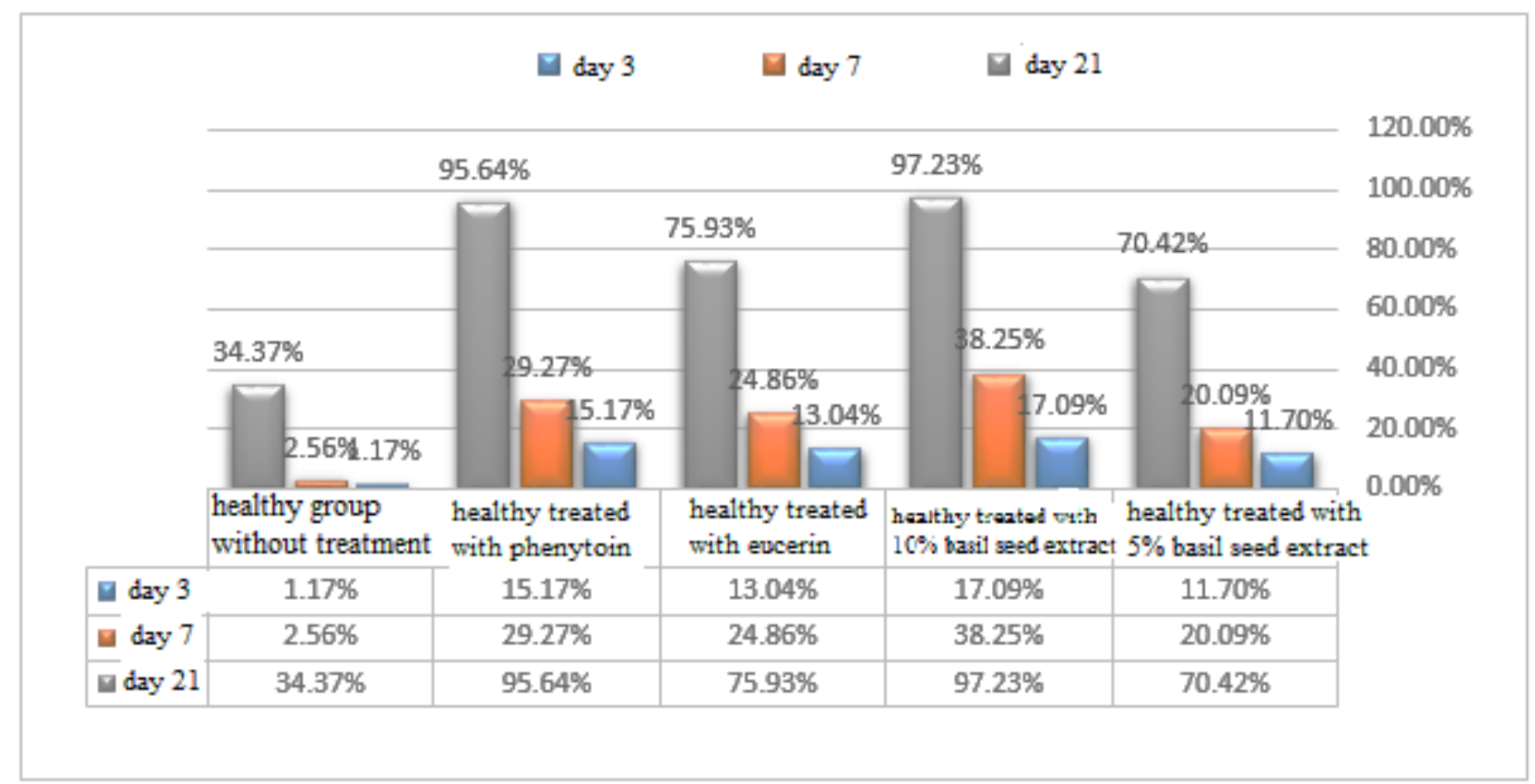

Graph 1. Comparison of the mean decrease in wound area compared to the first day in non-diabetic groups during the study period

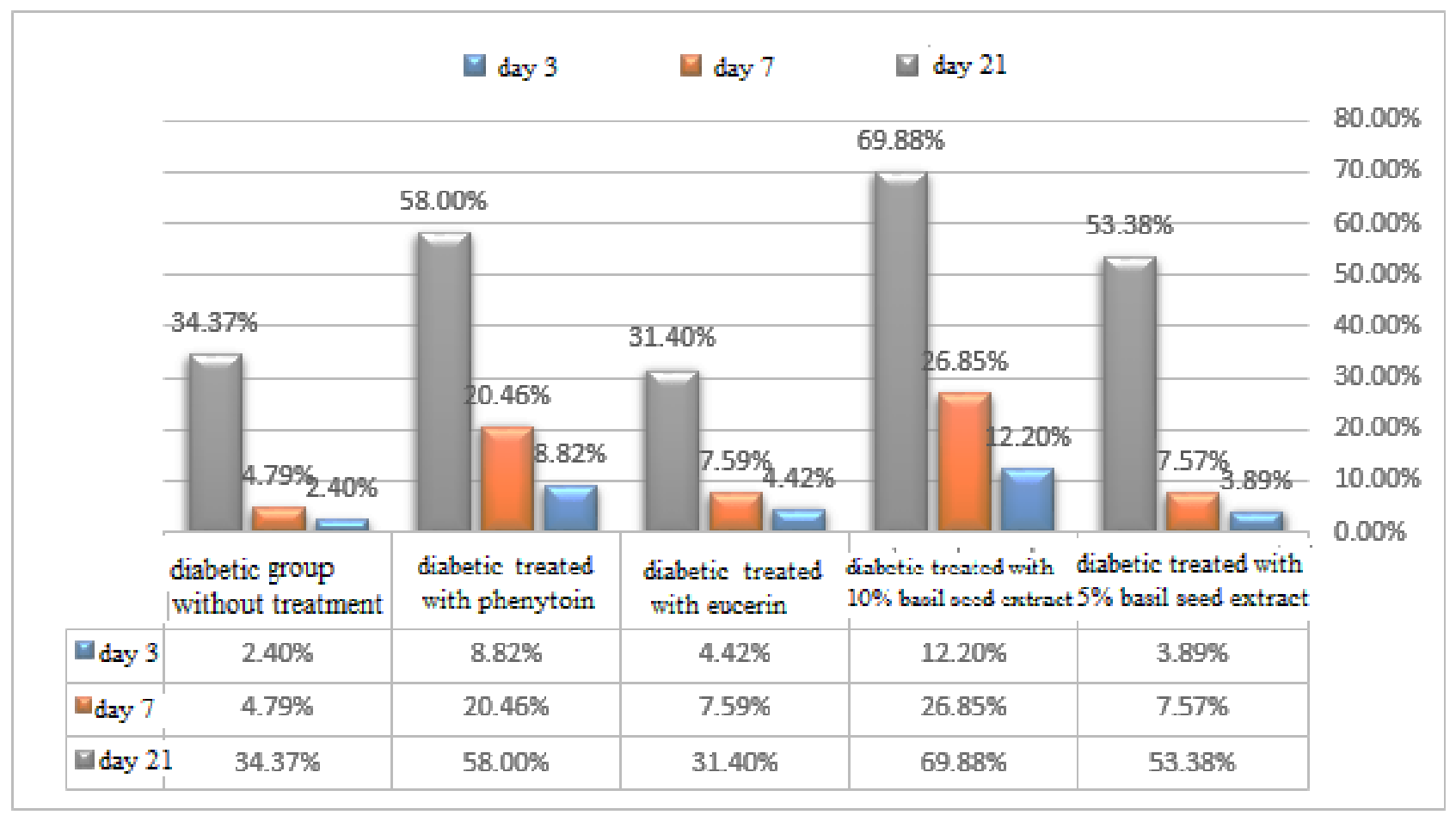

Graph 2. Comparison of the mean decrease in wound area compared to the first day in diabetic groups during the study period 
$5 \%$ basil extract

eucerin $\square$

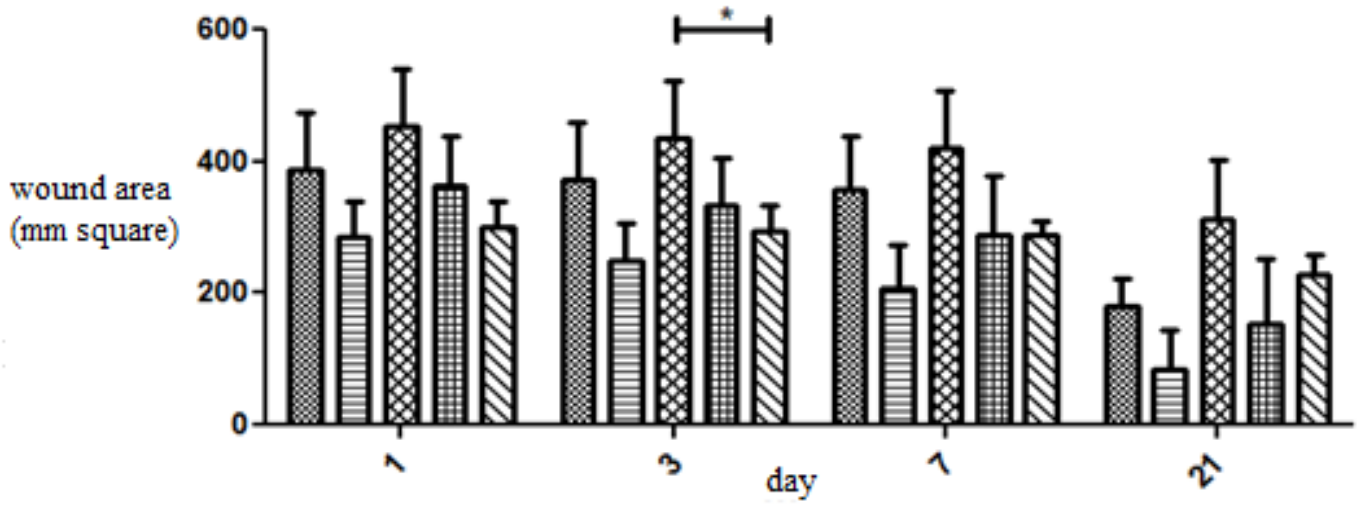

phenytoin min

control

Graph 3. Comparison of the wound area among diabetic rats during the study period

Healthy without treatment eucerin

Diabetic treated with phenytoin

Diabetic treated with phenytoin

Diabetic without treatment
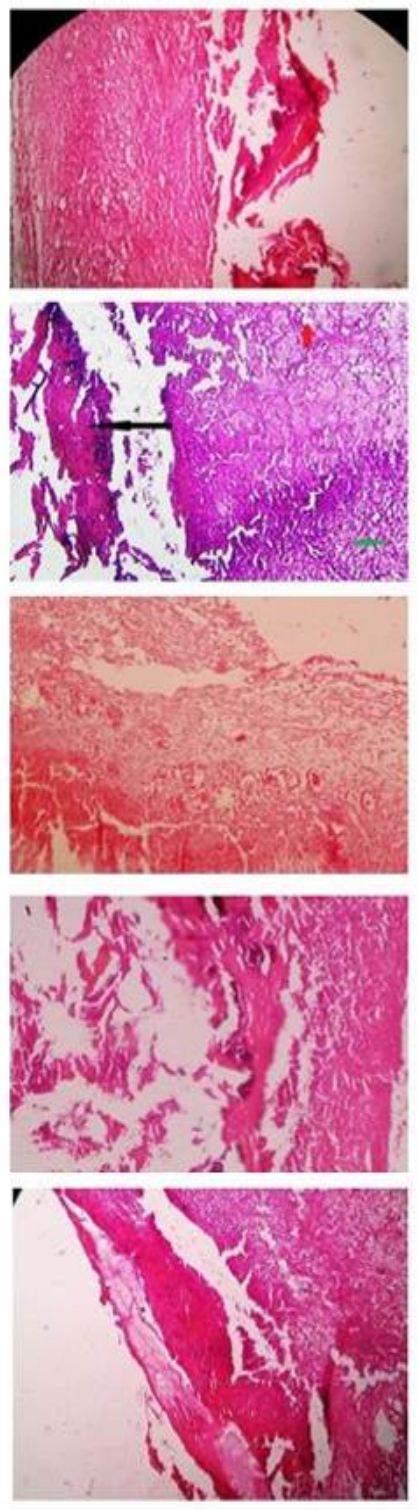
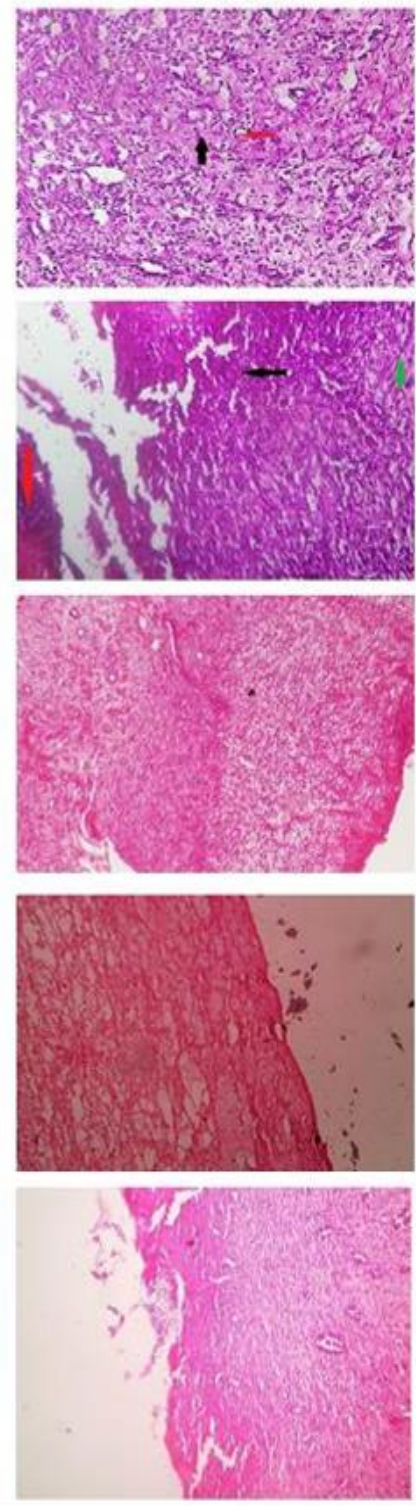
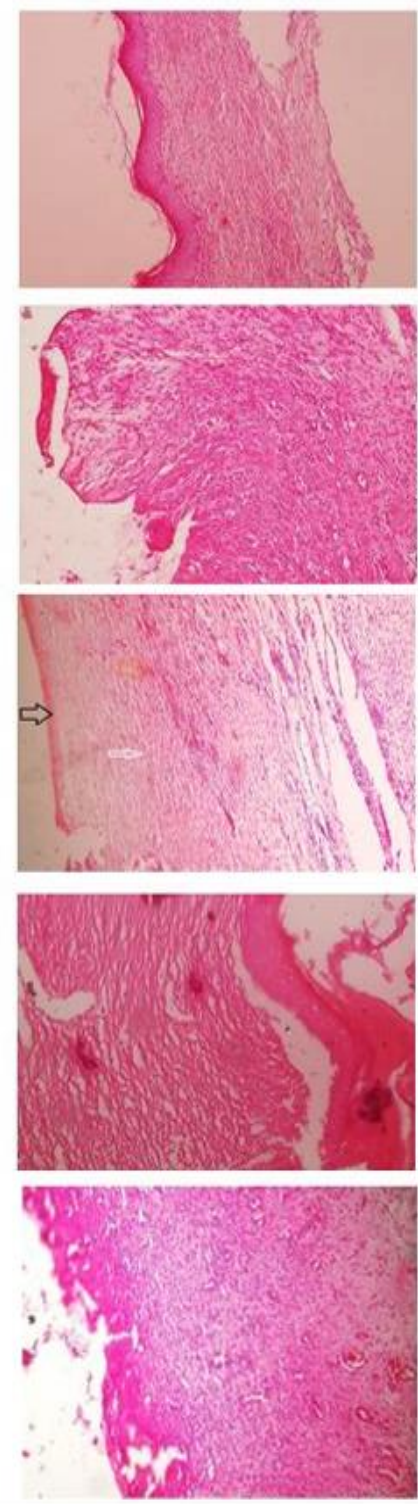

Figure 1. Histological section of wound healed on days 3,7, and 21 post-surgery 
Table 1. Results of histopathological examinations of wound 3, 7, and 21 days after wound healing

\begin{tabular}{|c|c|c|c|c|c|c|c|}
\hline Groups & Day & Inflammation & Bleeding & Angiogenesis & $\begin{array}{l}\text { Collagen } \\
\text { fiber }\end{array}$ & $\begin{array}{c}\text { Epithelium } \\
\text { Fiber }\end{array}$ & Clot \\
\hline \multirow{3}{*}{ Healthy without treatment } & 3 & +++ & +++ & ++ & + & - & - \\
\hline & 7 & ++ & +++ & + & + & - & - \\
\hline & 21 & + & + & + & ++ & + & - \\
\hline \multirow{3}{*}{ Diabetic without treatment } & 3 & ++ & ++ & ++ & + & - & + \\
\hline & 7 & +++ & + & + & + & - & ++ \\
\hline & 21 & + & + & + & ++ & - & - \\
\hline \multirow{3}{*}{ Healthy phenytoin } & 3 & + & + & ++ & + & - & ++ \\
\hline & 7 & + & - & ++ & ++ & - & - \\
\hline & 21 & - & - & - & +++ & ++ & - \\
\hline \multirow{3}{*}{ Diabetic phenytoin } & 3 & ++ & ++ & - & + & - & ++ \\
\hline & 7 & + & + & ++ & ++ & - & - \\
\hline & 21 & + & + & + & ++ & - & - \\
\hline \multirow{3}{*}{ Healthy eucerin } & 3 & ++ & + & + & + & - & ++ \\
\hline & 7 & ++ & ++ & ++ & ++ & - & - \\
\hline & 21 & + & - & - & ++ & + & - \\
\hline \multirow{3}{*}{ Healthy with $5 \%$ basil } & 3 & + & + & ++ & + & - & ++ \\
\hline & 7 & ++ & + & + & + & - & - \\
\hline & 21 & + & - & - & ++ & ++ & - \\
\hline \multirow{3}{*}{ Diabetic 5\%basil } & 3 & ++ & ++ & +++ & + & - & - \\
\hline & 7 & ++ & + & ++ & + & - & - \\
\hline & 21 & + & - & - & ++ & + & - \\
\hline \multirow{3}{*}{ Healthy $10 \%$ basil } & 3 & + & + & + & ++ & - & - \\
\hline & 7 & - & - & ++ & ++ & - & - \\
\hline & 21 & - & - & - & ++ & ++ & - \\
\hline \multirow{3}{*}{ Diabetic $10 \%$ basil } & 3 & + & + & + & + & - & +++ \\
\hline & 7 & + & + & + & + & - & - \\
\hline & 21 & + & + & - & + & + & - \\
\hline
\end{tabular}

+++: Severe ++: Moderate +: Light -: Absence

\section{CONCLUSION}

In general, based on the obtained results, particularly histopathologically, an excellent tendency to collagen formation and the lack of secondary infection in the site was witnessed, which is perhaps because of antimicrobial and antiinflammatory characteristics and strong phenolic antioxidants in basil. Therefore, these seeds can be used in the production of wound healing ointments.

\section{DECLARATION}

\section{Authors' contribution}

All authors have read and agreed to the published version of the manuscript. Mehran Hadi, Elham MoghtadaeiKhorasgani, and Mohammad Hossein Etesamnia contributed to the design and implementation of the research, the analysis of the results, and the writing of the manuscript.

\section{Competing interests}

The authors have no competing interests. In addition, we have no authorship or article publication conflict. Ethical issues (including plagiarism, consent to publish, misconduct, data fabrication and/or falsification, double publication and/or submission, and redundancy) have been checked by the authors.

\section{Acknowledgments}

The authors are grateful to the Faculty of Veterinary Medicine of Shahrekord Azad University.

\section{Ethical considerations}

Ethical issues (including plagiarism, consent to publish, misconduct, data fabrication and/or falsification, double publication and/or submission, and redundancy) have been checked by the authors.

\section{REFERENCES}

Adeli-Sardou M, Yaghoobi MM, Torkzadeh-Mahani M, and Dodel M (2019). Controlled release of lawsone from polycaprolactone/gelatin electrospun nanofibers for skin tissue regeneration. International Journal of Biological Macromolecules, 124: 478-491. DOI: https://www.doi.org/10.1016/j.ijbiomac.2018.11.237 
Amalraj A, and Gopi S (2017). Biological activities and medicinal properties of Asafoetida: A review. Journal of Traditional and Complementary Medicine, 7(3): 347-359. DOI: https://www.doi.org/10.1016/j.jtcme.2016.11.004

Aziz MA, Khan AH, Adnan M, and Izatullah I (2017). Traditional uses of medicinal plants reported by the indigenous communities and local herbal practitioners of Bajaur Agency, Federally Administrated Tribal Areas, Pakistan. Journal of Ethnopharmacology, 198: 268-281. DOI: https://www.doi.org/10.1016/i.jep.2017.01.024

Bagheri M, Molzemi S, Hadizadeh M, and Aminian M (2016). Study of alcohol extract of sesame on wound healing of diabetic male wistar rats. Journal of Neyshabur University of Medical Science, 3(4): 1-9. Available at: http://journal.nums.ac.ir/article-1-202$\underline{\text { en.html }}$

Brereton MF, Vergari E, Zhang Q, and Clark A (2015). Alpha-, delta-and PP-cells: Are they the architectural cornerstones of islet structure and co-ordination?. Journal of Histochemistry and Cytochemistry, 63(8): 575-591. DOI: https://www.doi.org/10.1369/0022155415583535

Denaro M, Smeriglio A, Barreca D, De Francesco C, Occhiuto C, Milano G, and Trombetta D (2020). Antiviral activity of plants and their isolated bioactive compounds: An update. Phytotherapy Research, 34(4): 742-768. DOI: https://www.doi.org/10.1002/ptr.6575

Everett E, and Mathioudakis N (2018). Update on management of diabetic foot ulcers. Annals of the New York Academy of Sciences, 1411(1): 153-165. DOI: http://www.doi.org/10.1111/nyas.13569

Filip S (2017). Basil (Ocimum basilicum L.) a source of valuable phytonutrients. International Journal of Clinical Nutrition and Dietetics, 3: 118-123. DOI: https://www.doi.org/10.15344/2456-8171/2017/118

Firoozeh E, Khodarahmi P, Naseh V, Shahedi V, Golgoo F, and Mohammad yari S (2019). Synergistic effect of treadmill exercise and green tea extract on cutaneous wound healing in diabetic mice. New Cellular and Molecular Biotechnology Journal, 9(34): 4756. Available at: http://ncmbjpiau.ir/article-1-1187-en.html

Foo YZ, Nakagawa S, Rhodes G, and Simmons LW (2017). The effects of sex hormones on immune function: A metaanalysis. Biological Reviews, 92(1): 551-571. DOI: https://www.doi.org/10.1111/brv.12243

Guo W, Tan HY, Chen F, Wang N, and Feng Y (2020). Targeting cancer metabolism to resensitize chemotherapy: Potential development of cancer chemosensitizers from traditional Chinese medicines. Cancers, 12(2): 1-21. DOI: https://www.doi.org/10.3390/cancers12020404

Gutiérrez-Grijalva EP, Picos-Salas MA, Leyva-López N, Criollo-Mendoza MS, Vazquez-Olivo G, and Heredia JB (2018). Flavonoids and phenolic acids from oregano: Occurrence, biological activity and health benefits. Plants, 7(1): 2-23. DOI: http://www.doi.org/10.3390/plants7010002

Ibrahim NI, Wong SK, Mohamed IN, Mohamed N, Chin KY, Ima-Nirwana S, and Shuid AN (2018). Wound healing properties of selected natural products. International Journal of Environmental Research and Public Health, 15(11): 2360. DOI: http://www.doi.org/10.3390/ijerph15112360

Khaksar S,Kesmati M, Rezaie A, Rasekh A(2011). Topical Estrogen Accelerates Wound Healing in Diabetic Rats. Iranian Journal of Endocrinology and Metabolism, 12(5):541-551. DOI: https://www.doi.org/10.1007/s00580-010-1151-x

Miri A, Khatami M, Ebrahimy O, and Sarani M (2020). Cytotoxic and antifungal studies of biosynthesized zinc oxide nanoparticles using extract of Prosopis farcta fruit. Green Chemistry Letters and Reviews, 13(1): 27-33. DOI: https://www.doi.org/10.1080/17518253.2020.1717005

Mirjalili MM, Faramarzi S, Esmaeilidehaj M, Zare Mehrjardi F, and Ebrahim Rezvani M (2017). Effect of aqueous extract of Morus nigra on skin wound healing in type 1 diabetic rats. Journal of Shahid Sadoughi University of Medical Sciences, 25(4): 264270. Available at: http://jssu.ssu.ac.ir/article-1-3875-en.html

Mostafavi S, Asadi-Gharneh HA, and Miransari M (2019). The phytochemical variability of fatty acids in basil seeds (Ocimum basilicum L.) affected by genotype and geographical differences. Food Chemistry, 276: 700-706. DOI: http://www.doi.org/10.1016/j.foodchem.2018.10.027

Pourmahdi O, and Faedmaleki F (2021). Comparative effect of ivy extract with geranium on shear wound healing in rats. Journal of Knowledge and Health in Basic Medical Sciences, 15(4): 43-50. DOI: http://www.dx.doi.org/10.22100/jkh.v4i15.2446

Reinke JM, and Sorg H (2012). Wound repair and regeneration. European Surgical Research, 49(1): 35-43. DOI: https://www.doi.org/10.1159/000339613

Sadoughi SD (2013). The effect of aqueous extract of Angoze gum on wound healing in streptozotocin-induced diabetic rats. Knowledge Horizon, 19(3): 129-135. Available at: https://iranjournals.nlai.ir/handle/123456789/633651

Salem AM, Ragheb AS, Hegazy M. G, Matboli M, and Eissa S (2019). Caffeic acid modulates miR-636 expression in diabetic nephropathy rats. Indian Journal of Clinical Biochemistry, 34(3): 296-303. DOI: https://www.doi.org/10.1155/2020/3960857

Shahrokh S, Aliye T, Yazdi M, Siavash M, and Aminorroaya A (2021). Bacterial profile and antimicrobial resistance patterns of infected diabetic foot ulcers in Iran: A systematic review and meta-analysis of cross-sectional studies. The International Journal of Lower Extremity Wounds, 1: 12-13. DOI: https://www.doi.org/10.1177/15347346211002715

Siljander H, Honkanen J, and Knip M (2019). Microbiome and type 1 diabetes. EBioMedicine, 46: 512-521. DOI: https://www.doi.org/10.1016/j.ebiom.2019.06.031

Veith AP, Henderson K, Spencer A, Sligar AD, and Baker AB (2019). Therapeutic strategies for enhancing angiogenesis in wound healing. Advanced Drug Delivery Reviews, 146: 97-125. DOI: https://www.doi.org/10.1016/j.addr.2018.09.010

Walko G, Castañón MJ, and Wiche G (2015). Molecular architecture and function of the hemidesmosome. Cell and Tissue Research, 360(2): 363-378. DOI: https://www.doi.org/10.1007/s00441-014-2061-z 